\title{
Gender differences in retinol metabolism are independent of $\beta$-carotene bioconversion
}

\author{
Anthony Oxley ${ }^{1}$, Philip Berry ${ }^{2}$, John Hesketh ${ }^{3}$, Alan V Boddy ${ }^{2}$ and Georg Lietz ${ }^{1}$ \\ ${ }^{1}$ Human Nutrition Research Centre, School of Agriculture, Food and Rural Development, ${ }^{2}$ Northern Institute for Cancer \\ Research and ${ }^{3}$ Institute for Cell and Molecular Biosciences; Newcastle University, UK
}

Gender-related differences in retinol and provitamin A carotenoid metabolism have previously been detected, with higher retinol concentrations in men, and on the contrary, higher $\beta$-carotene concentrations in women ${ }^{(1)}$. This reversed relationship suggests a higher $\beta$-carotene to retinol conversion rate in males ${ }^{(1)}$. Furthermore, lower conversion efficiency is correlated with BMI in women, but not in men $^{(2)}$. We investigated retinol metabolism and $\beta$-carotene conversion efficiency in 23 female and 19 male volunteers by co-administering $2 \mathrm{mg}\left[{ }^{13} \mathrm{C}_{10}\right]-\beta$-carotene and $1 \mathrm{mg}\left[{ }^{13} \mathrm{C}_{10}\right]$-retinyl acetate. Relative absorption of $\beta$-carotene in the first 24 hours represented $11 \%$ of total ingested $\left[{ }^{13} \mathrm{C}_{10}\right]-\beta$-carotene, with an inter-individual coefficient of variation of $49 \% .\left[{ }^{13} \mathrm{C}_{10}\right]-\beta$-carotene plasma concentration within the first 24 hours post-dose were significantly inversely related to the ability to convert $\beta$-carotene into retinyl-palmitate $(r=-0.89$; $p<0.001)$. More importantly, significantly higher plasma concentrations of preformed $\left[{ }^{13} \mathrm{C}_{10}\right]$-retinol and bio-converted $\left[{ }^{13} \mathrm{C}_{5}\right]$-retinol were found in men compared to women (Figure 1), although plasma $\left[{ }^{13} \mathrm{C}_{10}\right]-\beta$-carotene concentrations were similar between the genders. Interestingly, differences in retinoid concentrations are independent from the ability to cleave $\left[{ }^{13} \mathrm{C}_{10}\right]-\beta$-carotene, since both retinyl palmitate/ $\beta$-carotene and the newly-formed retinoid reference dose ratios are not significantly different between men and women (Figure 1).
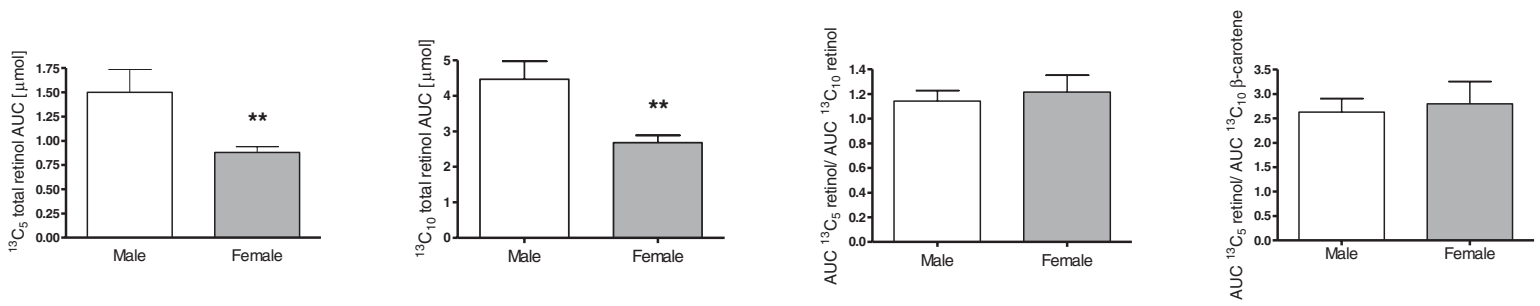

Fig. 1. Effect of gender on plasma retinol concentrations and provitamin A conversion efficiency (AUC = Area under the curve for the first 24 hours post-dose).

In summary, our isotope dilution technique revealed that men have higher circulating retinol concentrations compared to women, and that this difference is independent of provitamin A conversion efficiency. We hypothesize that a gender specific effect on metabolic flux between different tissues could explain this difference.

This work was supported by the BBSRC.

1. Faure H, Preziosi P et al. (2006) Eur J Clin Nutr 60(6), 706-17.

2. Tang G, Qin J et al. (2003) Am J Clin Nutr 78(2), 259-66. 